Archives of Emergency Medicine, 1993, 10, 216-219

\title{
Telephone advice in the accident and emergency department: a survey of current practice
}

\author{
R. J. EVANS, M. MCCABE, H. ALLEN*, T. RAINER \& \\ P. W. RICHMOND
}

Department of Emergency Medicine, Cardiff Royal Infirmary, Newport Road, Cardiff CF2 $1 S Z$ and ${ }^{*}$ Department of Emergency Medicine, Morriston Hospital, Swansea SA6 6NL

\section{SUMMARY}

The objective of this study was to assess the standard of advice given by telephone by accident and emergency (A\&E) departments following patients' enquiries. In orde $\vec{\bullet}$ to do this patient enquiries were simulated and a telephone questionnaire w carried out. The study was carried out in 18 major and 16 minor A\&E departmence in Wales. Results achieved were that overall, correct telephone advice was given to 72 of 97 simulated patients $(74 \%)$. Sixty calls were dealt with by the nursing staff $(62 \%)$ who gave correct advice on $41(68 \%)$ occasions. No A\&E department had a formal policy nor provided staff training for handling patients' enquiries by $\stackrel{\mathbb{D}}{\circ}$ telephone. It is concluded that $A \& E$ departments should train designated members $\overrightarrow{\vec{O}}$ of staff, preferably the triage nurse, who would formally deal with telephone enquiries requiring medical advice. There should be formal documentation of the enquiry and advice proffered as part of a departmental policy.

\section{INTRODUCTION}

Patients frequently telephone the A\&E department for medical advice. The Leicester Royal Infirmary with a catchment population of almost 900000 , receives an average of 15 such calls per day and the majority of calls are relatively easily dealt with by the triage nurse (Singh et al., 1991). Occasionally the calls are not straightforward, e.g. requesting help and advice with cardiopulmonary resuscitation or how to deal N with a potential suicide (Wheeler, 1989). It would seem appropriate that staff

Correspondence: Dr R. J. Evans, Department of Emergency Medicine, Cardiff Royal Infirmary, Newoport Road, Cardiff CF2 1SZ. 
handling such enquiries have been trained appropriately and are suitably experienced. Although many departments 'officially' refuse to offer telephone advice, de facto advice is usually given. Once advice is offered, a legal obligation and responsibility for that advice has been assumed (Dunn, 1985). Documentation of the telephone enquiry with details of the patient and advice given would be invaluable if a medicolegal problem arose as well as allowing audit and training.

The aims of this study were to assess the standard of advice given by A\&E departments in response to simulated telephone enquiries and to discover how many A\&E departments in Wales have a formal policy for managing clinical enquiries by telephone.

\section{SUBJECTS AND METHODS}

All the major (18) and minor (16) (with $>5000$ new attendances) A\&E departments in Wales were surveyed. A researcher (RT) telephoned the A\&E department posing as a patient with one of three clinical problems. The 'patient', a 25-year-old male, had no past medical problems, was on no medication and had no allergic history. The three telephone enquiries were as follows:

(1) Was a tetanus booster required following a superficial dog bite to the lower leg?

Further enquiry would elicit that the last booster had been 6 years previously when he had received a full primary immunization course. A correct response was that no further immunization was required (Department of Health, Welsh Office, 1990)

(2) Should the patient attend the A\&E department for an X-ray with lower back pain which developed whilst lifting a weight? Direct questioning would elicit no neurological symptoms or past history of back problems.

A correct response would be to advise the patient that an X-ray was not required but referral to his general practitioner for a full examination, analgesia and advice as appropriate (McCall \& Butt, 1987)

(3) Should the patient attend the A\&E department after twisting his ankle as he was having difficulty walking?

A correct response was to advise the patient to attend the department or his own GP for clinical examination (DeLacey \& Bradbrooke, 1979).

During the conversation with the staff an attempt was made by the 'patient' to extract the status of the health care worker if this was not volunteered.

Following the initial part of the survey, departments were telephoned and asked about their policy for giving telephone advice. If there was no formal policy they were questioned as to whom would answer telephone enquiries requiring medical advice, whether any documentation of the enquiry was recorded and whether they operated a triage nurse within their department.

\section{RESULTS}

Of the $97 \mathrm{~A} \& \mathrm{E}$ telephone enquiries only four $(4 \%)$ calls were directed to a doctor, 


\section{8}

R. J. Evans et al.

advice was offered by the nursing staff on 60 (62\%) occasions and $16(16 \%)$ occassions by the reception staff. In the remaining $17(18 \%)$ of calls the status of the member of staff was not able to be ascertained.

The health care worker introduced themselves by name and status on four occasions. The status was stated on a further 25 occasions and these were all by $\overrightarrow{0}$ nursing staff. Further questioning by the health care worker was undertaken in only seven $(7 \%)$ calls.

A total of $72(74 \%)$ of answers were correct (see Fig. 1) with the following breakdown by the status of the health care worker - doctor $4 / 4(100 \%)$; receptionist 15/16 (94\%) and nurse $41 / 60(68 \%)$.

No department had guidelines, protocols nor offered staff training for dealing with patients' telephone enquiries. Only $3 / 34(9 \%)$ departments stated that they would document their telephone enquiries yet in practice this occurred in only $2 / 97(2 \%)$ calls. Only $5 / 34(15 \%)$ departments had operational triage nurses.

\section{DISCUSSION}

Telephone advice given in the A\&E department can be extremely hazardous because a complete history is unlikely, a physical examination is impossible, documentation is difficult and instructions are often misunderstood (Luten, 1988

In our survey the telephone advice to a simulated patient was considered corre $8 \vec{\bullet}$ in only $72 / 97(74 \%)$ of calls. Documentation of calls and advice given was rarely practised. All departments deemed it necessary for medical advice to be provided by medical or nursing staff yet on 16 occasions a receptionist provided advice. The nursing staff were the only group to introduce their name and/or status spontaneously which does not meet the standard as suggested in 'The Citizens Charter'.

A\&E departments need to recognize that telephone advice will be sought and must have an effective and appropriate policy. An extension of telephone advice is the concept of telephone triage where prospective patients are encouraged to telephone the triage nurse before they attend, whenever practical (Buckles \& Carew-McColl, 1991). The triage nurse will then decide whether the patient requires attention at the A\&E department or whether the patient could and should see their GP or be referred to another source.

There seems to be a need for recommendations and guidelines on telephone advice given to patients. As no such guidelines currently exist, however, it seems $\subseteq$

Fig. 1. Response to telephone enquiries 1-3

\begin{tabular}{lcllc}
\hline Question & $\begin{array}{l}\text { Total no. } \\
\text { enquiries }\end{array}$ & $\begin{array}{c}\text { Correct } \\
\text { response }\end{array}$ & $\begin{array}{l}\text { Major unit } \\
\text { correct (\%) }\end{array}$ & $\begin{array}{l}\text { Minor unit } \\
\text { correct (\%) }\end{array}$ \\
\hline 1 & 35 & $22(63)$ & $14 / 19(74)$ & $8 / 16(50)$ \\
2 & 32 & $20(63)$ & $10 / 19(53)$ & $10 / 13(77)$ \\
3 & 30 & $30(100)$ & $19 / 19(100)$ & $11 / 11(100)$ \\
\hline
\end{tabular}


reasonable to suggest that $A \& E$ departments should review their current policy. It is suggested that patients' enquiries by telephone be directed to a designated nurse, preferably the triage nurse or otherwise an experienced nurse who will have had the relevant training, augmented by departmental protocols. Ideally all telephone enquiries should be channelled through one telephone extension and a designated member of the nursing staff would be identified to answer calls on this telephone. All calls and advice given should be documented for medicolegal purposes and to enable audit.

\section{ACKNOWLEDGEMENTS}

The authors would like to thank Dr. R. C. Evans for his help and Mrs. G. Beasley for typing the manuscript.

\section{REFERENCES}

Buckles E. \& Carew-McColl M. (1991) Triage by telephone. Nursing Times 87, 26-28.

De Lacey G. J. \& Bradbrooke S. (1979) Rationalising requests for X-ray examination of acute ankle injuries. British Medical Journal 1, 1597-1598.

Department of Health, Welsh Office (1990) Scottish Home and Health Department. Immunisation Against Infectious Disease. HMSO, London.

Dunn J. M. (1985) Warning - giving telephone advice is hazardous to your professional health. Nursing 8, 40-41.

Luten R. C. (1988) Problems in Paediatric Emergency Medicine, pp. 45-59. Churchill Livingstone, Edinburgh.

McCall I. W. \& Butt W. P. (1987) The radiological diagnosis of low back pain. Current Orthopaedics 1, 375-382.

Singh G., Barton D. \& Bodiwala G. G. (1991) Accident and emergency department's response to patients' enquiries by telephone. Journal of the Royal Society of Medicine 84, 345-346.

Wheeler S. Q. (1989) ED Telephone triage: lessons learned from unusual calls. Journal of Emergency Nursing 15, 481-487. 